\title{
A importância da disciplina Educação em Saúde na Amazônia para docentes da área da saúde: Um relato de Experiência
}

The importance of Health Education discipline in the Amazon for healthcare teachers: A report of experience

La importancia de la asignatura de Educación para la Salud em la Amazonía para los profesores del área de la salud: Un informe de experiencia

\section{Resumo}

Objetivo: Relatar a experiência vivida pelos alunos de mestrado profissional durante a da disciplina Educação em Saúde na Amazônia, evidenciando assim a qualificação da formação docente de profissionais de saúde. Métodos: Este relato baseia-se na experiência de 16 alunos do curso de Pós-graduação de Mestrado Profissional Ensino em Saúde na Amazônia da Universidade do Estado do Pará (UEPA) durante a disciplina Educação em Saúde na Amazônia. Os temas abordados nas aulas foram: Competências e saberes dos docentes no ensino superior em saúde, DCN e os currículos inovadores em saúde, teorias da aprendizagem, métodos de ensino, tecnologias educacionais e avaliação da aprendizagem. Relato de experiência: Os alunos vivenciaram metodologias ativas na prática enquanto aprendiam o conteúdo da disciplina. As atividades propostas pelos professores foram: mapa conceitual, Aprendizagem Baseada em Problemas (PBL), Júri-simulado e Aprendizagem baseada em equipes (TBL). Essas estratégias permitiram uma aula excelente e motivadora, pois a absorção do conteúdo se tornou mais fácil, agradável, dinâmica e interativa. Considerações finais: A disciplina Educação em Saúde na Amazônia entregou como benefício aos discentes conhecimentos, novas estratégias e prática para capacitar e aprimorar o desempenho em sala de aula como docente, construindo um ambiente que facilite o processo de ensino-aprendizagem do aluno.

Palavras-chave: Profissional de saúde; Docentes; Educação superior; Ensino; Metodologias ativas.

\begin{abstract}
Objective: Report the experience of professional master degree students during the discipline Health Education in the Amazon, thus showing the qualification of teaching training for health professionals. Method: This report is based on the experience of 16 students from the Postgraduate Professional Master's Degree Course in Health Education in the Amazon of the State University of Pará (UEPA) during the discipline in Health Education in the Amazon. The topics covered in the classes were: Skills and knowledge of teachers from higher education in health, DCN and innovative curricula in health, learning theories, teaching methods, educational technologies and learning assessment. Experience report: Students experienced active methodologies in practice while learning the content of the discipline. The activities proposed by the teachers were: concept map, Problem Based Learning (PBL), Simulated Jury and Team Based Learning (TBL). These strategies allowed an excellent and motivating class, as the absorption of the content became easier, pleasant, dynamic and interactive. Final considerations: The subject Health Education in the Amazon
\end{abstract}


provided the students with knowledge, new strategies and practices to train and improve their performance in the classroom as a teacher, building an environment that facilitates the student's teaching-learning process.

Keywords: Health care professional; Facult; Higher education; Teaching; Active methodologies.

\begin{abstract}
Resumen
Objetivo: Informar la experiencia de los estudiantes de maestría profesional durante el curso de Educación para la Salud en la Amazonía, evidenciando así la calificación de la formación docente para profesionales de la salud. Método: Este informe se basa en la experiencia de 16 estudiantes del Curso de Postgrado Profesional de Maestría en Educación para la Salud en la Amazonía de la Universidad Estatal de Pará (UEPA) durante el curso de Educación para la Salud en la Amazonía. Los temas tratados en las clases fueron: Habilidades y conocimientos de los docentes de educación superior en salud, DCN y currículos innovadores en salud, teorías del aprendizaje, métodos de enseñanza, tecnologías educativas y evaluación del aprendizaje. Informe de experiencia: Los estudiantes experimentaron metodologías activas en la práctica mientras aprendían el contenido de la disciplina. Las actividades propuestas por los profesores fueron: mapa conceptual, Aprendizaje Basado en Problemas (PBL), Jurado Simulado y Aprendizaje Basado en Equipos (TBL). Estas estrategias permitieron una clase excelente y motivadora, ya que la absorción del contenido se hizo más fácil, placentera, dinámica e interactiva. Consideraciones finales: La asignatura Educación para la Salud en la Amazonía brindó a los estudiantes conocimientos, nuevas estrategias y prácticas para capacitar y mejorar su desempeño en el aula como docente, construyendo un ambiente que facilite el proceso de enseñanza-aprendizaje del alumno.
\end{abstract}

Palabras clave: Profesionales de la salud; Docentes; Educación superior; Enseñanza; Metodologías activas.

\title{
1. Introdução
}

A formação do docente do ensino superior tem ganhado destaque atualmente, já que uma característica comum que eles apresentam independente da área de atuação é a formação pedagógica ou didática precárias ou ausentes (Valente \& Viana, 2010). O curso de nível superior, quando comparado ao ensino infantil, fundamental e médio, é o único que não requer formação específica para o magistério. Embora o professor de ensino superior quase sempre apresente Mestrado e/ou Doutorado, nem sempre tem afinidade com abordagens ou concepções de ensino-aprendizagem que o habilite a exercer a docência com a mesma eficiência com que exerce sua profissão de origem (Valente \& Viana, 2010; Freitas et al., 2016).

Além disso, o ensino superior em saúde está com grande foco nessas diversas discussões quando o assunto é a formação e desenvolvimento dos docentes que atuarão nas instituições de nível superior (Pinto \& Pepe, 2007; Costa, 2010; Soares \& Cunha, 2010). O desafio é romper com o modelo fragmentado e tecnicista, buscando a formação de profissionais da área da saúde mais humanistas, com condições de trabalho em equipe, de forma integrada e almejando a integralidade da atenção à saúde (Colares \& Oliveira, 2018; Treviso \& Costa, 2017).

Diante dessa realidade, o programa de pós-graduação de Mestrado profissional de Ensino em Saúde na Amazônia (ESA) da Universidade do Estado do Pará (UEPA) apresenta como um de seus objetivos preparar profissionais com capacidade técnica, pedagógica e científica para atender a demanda específica do mercado de trabalho no ensino e assistência na saúde. O programa é uma estratégia de produção de conhecimento e inovação sobre o Ensino na Saúde a partir da problematização das práticas hoje envolvidas na formação de profissionais, especialmente no âmbito dos serviços de saúde (Universidade do Estado do Pará, 2021).

A matriz curricular desse mestrado envolve disciplinas e outros componentes curriculares organizados, voltados para a formação de docentes e pesquisadores, utilizando diversas estratégias de ensino-aprendizagem, tais como Aprendizagem Baseada em Problemas (PBL), Aprendizagem Baseada em Equipes (TBL), problematização, simulação, seminários, oficinas, estágio docência dentre outras (Universidade do Estado do Pará, 2021).

A disciplina Educação em Saúde corresponde ao segundo módulo ofertado no programa e aborda temas muito importantes para a formação e preparação do docente da área da saúde. 
Sendo assim, o objetivo deste estudo é relatar a experiencia vivida pelos alunos de mestrado profissional durante a disciplina Educação em Saúde na Amazônia, evidenciando assim a qualificação da formação docente de profissionais de saúde.

\section{Metodologia}

Trata-se de um estudo com abordagem qualitativa, descritiva, do tipo relato de experiência. A pesquisa qualitativa tem como objetivo entender o comportamento das pessoas, suas opiniões, seus conhecimentos, suas atitudes, suas crenças e seus medos, estando relacionada ao significado que as pessoas atribuam as suas experiências do mundo e como entendem o mundo em que vivem. (Vieira \& Hossne, 2015).

Esse relato baseia-se na experiência de 16 discentes do curso de Pós-graduação de Mestrado Profissional Ensino em Saúde na Amazônia (ESA) da Universidade do Estado do Pará (UEPA), durante a disciplina Educação em Saúde na Amazônia realizada no mês de março do ano de 2019, Campus II, no Centro de Ciências Biológicas e da Saúde (CCBS), na cidade de Belém-Pará. Teve duração de 3 dias e os temas abordados nas aulas foram: Competências e saberes dos docentes no ensino superior em saúde, DCN e os currículos inovadores em saúde, teorias da aprendizagem, métodos de ensino, tecnologias educacionais e avaliação da aprendizagem.

Esta disciplina é de caráter obrigatórios do programa. Ela foi ministrada por dois professores do corpo docente do mestrado da instituição. Os objetivos do módulo eram: Conhecer as concepções da educação dos profissionais de saúde e as competências e saberes dos docentes; Identificar os pressupostos das teorias da aprendizagem e sua relação com o modelo de avaliação da aprendizagem; Conhecer as diferentes Diretrizes Curriculares dos cursos da saúde e as diferentes modalidades de currículo; Identificar as tecnologias educacionais e metodologias de ensino.

Por questões éticas, os nomes dos professores e dos alunos, não serão mencionados durante o relato de experiência.

\section{Relato de Experiência}

No primeiro dia de aula, a discussão foi sobre as "Competências e saberes dos docentes no ensino superior em saúde", no qual a estratégias de aprendizagem utilizadas pelos professores foi o mapa conceitual. A turma foi dividida em quatro equipes e foi proposto para cada uma a construção de mapas conceituais sobre a temática da aula, baseando-se em conhecimentos prévios e norteados por artigos disponibilizados na ementa da disciplina. Observou-se que as equipes construíram os mapas com formas e articulações diferentes, o que enriqueceu a discussão e exposição dos trabalhos, bem como a construção de conhecimento acerca dos saberes docentes de forma sólida e criativa.

O segundo dia de aula teve como tema "Métodos de ensino", apresentando um formato bem diversificado para os alunos durante esse momento, já que era possível aprender e vivenciar as técnicas de metodologias ativas que facilitam a aprendizagem como o PBL, TBL e júri-simulado, ao mesmo tempo que eram inseridos outros conteúdos necessários do módulo durante a aplicação dessas atividades. Ou seja, temas como "Teorias da aprendizagem" aprendidos no modelo PBL, "Avaliação da aprendizagem" no modelo TBL e o próprio "Métodos de ensino" interligado com o processo ensinoaprendizagem durante a realização de um Júri-simulado.

Uma "mini" sessão de tutoria no formato PBL foi sugeria para trabalhar o conteúdo "Teorias da Aprendizagem". Devido o curto tempo da disciplina, foi simulada uma sessão com abertura e fechamento no mesmo dia. A turma foi dividida em dois grandes grupos para esta tarefa. Durante este momento percebeu-se que apesar da maioria dos estudantes atuarem como professores ou preceptores em cursos na área da saúde, apenas 3 estudantes (17\%) possuíam a experiência de 
participação em uma sessão de tutoria e apenas um dos estudantes (5\%) teve uma formação acadêmica com metodologias ativas, evidenciando a pouca experiência do grupo com o PBL.

Outra atividade realizada foi o júri simulado. O disparador para início da discussão foi a situação hipotética da reprovação de alunos em uma disciplina de um curso de saúde e a possível causa seria devido as metodologias de ensino utilizadas, sendo esta, o réu. Em seguida a turma foi dividida em três grupos, na qual, por meio de um sorteio, os grupos receberam as tarefas: primeiro grupo atuaria na defesa dos métodos de ensino (defensoria pública), o segundo grupo seria de acusação às abordagens metodológicas e possível culpado desta reprovação (promotoria) e a terceira equipe atuaria como os juízes, que após a explanação dos argumentos prós e contra anunciaria a sentença em relação a hipótese inicial.

Para finalizar, no terceiro e último dia da disciplina, ocorreu uma breve sessão de TBL, na qual os artigos sobre "Avaliação da aprendizagem" da ementa do curso haviam sido solicitados para leitura individual previa. A primeira etapa da aula foi a aplicação de um teste com questões de múltipla escolha pelos professores sobre o tema em questão para ser realizado de maneira individual. Depois, a turma foi dividia novamente em quatro equipes, e o teste foi refeito em grupo, sendo este um momento de discussão e debate para alcance de um gabarito em comum no coletivo. Em seguida, cada grupo expôs suas respostas para a turma e poderia escolher entre manter ou mudar a alternativa como resposta final. Em seguida, os professores revelaram o gabarito correto, comentando as alternativas de cada questão.

\section{Discussão}

Durante toda a disciplina, os diferentes temas abordados exigiram que os alunos fossem divididos em grupos, permitindo assim, uma maior interação entre os participantes, debates, trocas de experiências docentes/ preceptor, trabalho em equipe e redução de um vínculo tradicional de ensino. Ao mesmo tempo em que se aprendia sobre ensino em saúde e metodologias ativas, era possível vivenciar e praticar o que se tinha como objetivo aprender. Além de facilitar a aprendizagem da disciplina, foi possível observar como a desconstrução de uma sala de aula tradicional é importante para o desenvolvimento das habilidades do discente.

Enquanto se aprendia sobre os desafios na relação professor e alunos e a busca de um processo de ensinoaprendizagem mais eficiente, a montagem do mapa conceitual permitiu a organização de ideias debatidas por cada grupo, fechamento de uma mesma linha de raciocínio da turma com orientações e correções feitas pelos professores durante a construção e apresentação de cada mapa conceitual, e melhor compreensão e fixação do conteúdo que estava sendo desenvolvido.

O mapa conceitual permite aos alunos organizar seus pensamentos, entender os conceitos estudados e construir uma ferramenta visual que auxilia na retenção de conhecimento. O professor visualiza com maior clareza a forma pela qual o aluno organiza sua estrutura de conhecimento podendo regular uma aprendizagem mais eficiente, pois o professor tem condições de individualizar seus comentários acerca do entendimento conceitual dos seus alunos (Correia et al., 2016; Gouvêa, et al., 2016, Mukhopadhyay et al, 2019; Srivastava, Srivastava \& Chandrasekharan, 2021). Esses são fatores identificados e alcançados durante o módulo.

Ao término da "mini" sessão de tutoria, os professores solicitaram o feedback dos alunos em relação a atividade proposta. A fala de um dos alunos traduziu o quanto foi enriquecedora à atividade:

"Apesar da tutoria ter ocorrido em apenas algumas horas, a experiência foi surpreendente, todos no grupo foram participativos. $O$ mais difícil foi conseguir organizar todas as ideias no papel, com certeza a partir desse momento 
me sentirei mais capacitado para introduzir em minha prática docente a metodologia do PBL, obedecendo aos passos propostos e me aprofundarei um pouco mais no assunto, diferentemente de hoje que não tivemos tanto tempo assim.".

Outro relato que destaca-se é fala de um aluno com experiência na tutoria, quando salienta:

"Tivemos dificuldade de conduzir a discussão em um grupo tão heterogêneo e multidisciplinar, além disso, com os objetivos não definidos no início, acabei contribuindo mais do que deveria nas discussões, porém avalio a experiência de forma muito positiva, tendo em vista que foi a primeira experiência de muitos mestrandos".

A PBL permite uma aprendizagem construtivista, onde o aluno cria estruturas para organizar e recuperar informações apropriadas (Bodagh, Birch, J., \& Ricketts, 2017; Al-Azri \& Ratnapalan, 2014). É considerada um método desafiador, levando o aluno a desenvolver de habilidades como: pensamento crítico, julgamento baseado na análise, avaliação e inferência extraídas das evidências e explicar o processo de raciocínio no qual seu julgamento crítico é baseado (Wosinski et al., 2018; Jin \& Bridges, 2014). Os alunos conseguiram vivenciar um pouco desse método, tornado mais fácil a compreensão de como ele funciona e percebendo como o processo de aprendizagem é desenvolvido nele.

Durante o júri-simulado, todas as etapas propostas foram seguidas e culminaram no julgamento. Nessa atividade foi possível aliar um momento de descontração pelas encenações e performance dos alunos envolvidos, somado ao aprendizado, onde os argumentos foram muito bem construídos e debatidos, havendo uma troca de conhecimentos significativa, já que as arguições e defesas tinham embasamento científico. Observou-se também a imparcialidade do júri que soube apresentar seu parecer de forma coerente e fundamentada de acordo com o que previa a ementa desta disciplina.

O júri-simulado permite aprofundamento dos conhecimentos do aluno em determinados assuntos, já que precisa estabelecer relações entre os temas para argumentar de forma favorável ou contrária. A estratégia promove discussões de vários pontos de vista sobre o mesmo tema, divide opiniões, auxilia no processo de senso crítico, participativo e reflexivo (Alcântara et al., 2015; Lima, Sousa, \& Sitko, 2021). Essas características foram observadas durante a experiência dos mestrandos na aula.

Durante o TBL, os grupos tiveram um bom entrosamento e boas discussões para definirem a resposta correta que representaria o grupo todo em cada questão. Foi interessante perceber como cada integrante dos grupos defendiam seus posicionamentos e tentavam comprovar com seus conhecimentos prévios e leituras do material científico para embasar a escolha da resposta que acreditavam ser a certa.

O TBL é uma abordagem projetada para permitir a aprendizagem de maneira envolvente em que o instrutor forneça feedback frequente aos alunos. Ela vai muito além da aquisição básica de fatos, enfatiza a importância de aplicar o conhecimento a cenários da vida real por meio de discussões intragrupais e intergrupais de problemas que são projetados para fomentar raciocínios e debates complexos (Koh et al., 2020; Burgess et al., 2020). A turma conseguiu reconhecer essas características durante a aula.

As metodologias ativas são importantes para iniciar o processo de ensino em que o discente assume autonomia sobre o seu conhecimento e não apenas receptor de informações. São estratégias metodológicas visando a atuação do professor como facilitador ou orientador do estudante, que irá pesquisar, refletir e decidir por ele mesmo, diante de situações problemas, atingindo os objetivos de aprendizagem propostos. $\mathrm{O}$ aprender pode ser tanto em nível individual quanto coletivo, a partir de experiências reais ou simuladas, visando solucionar, com êxito, desafios em diferentes contextos (Colares \& Oliveira, 2018; Mello, Alves \& Lemos, 2012). Essas características foram vivenciadas e experimentadas durante o processo de aprendizagem do módulo. 
O planejamento dos professores dessa disciplina foi excelente e motivador, pois a absorção do conteúdo se tornou mais fácil, agradável, dinâmico e interativo. Além de aprender os conteúdos propostos, foi possível entender a importância em levar esses conhecimentos e técnicas para a prática docente/preceptor. Vivenciar metodologias ativas enquanto se aprende o conteúdo de Educação em Saúde, permitiu a idealização das mudanças almejadas na sala de aula, visando o melhor desenvolvimento das habilidades e competências dos alunos.

Essa disciplina permitiu que aqueles que já haviam feito e/ou conheciam as técnicas, pudessem aprimorar ou ajudar os que não conheciam e/ou nunca haviam vivenciado a conhecer e entender como funcionam. Ser parte desse processo trouxe um novo olhar da prática docente, permitiu compreender que os métodos tradicionais não devem ser excluídos, porém existem diversas formas de trabalhar com o aluno e tornar a aprendizagem mais eficiente.

Apesar da limitação imposta pelo tempo e a grande quantidade de conteúdo a serem abordados, a participação dos alunos foi efetiva, assídua e decisiva nesse processo bem como o direcionamento dos professores/tutores que se mostraram extremamente organizados, capacitados e conduziram com excelência os trabalhos desenvolvidos. Fazer parte desta disciplina encoraja o professor a aprimorar o docente que deseja e deve ser para os alunos, no qual o principal objetivo é facilitar o processo de ensino-aprendizagem.

\section{Considerações Finais}

O profissional de saúde mais crítico, reflexível e humanista desejado para o mercado de trabalho atual, aparentemente está mais próximo da realidade quando o ambiente da aprendizagem se parece com o vivenciado durante esta disciplina. Não é um ensino baseado na punição e nem na seleção dos mais inteligentes, é uma busca pela redução das barreiras do conhecimento, motivação da capacidade da autoaprendizagem do aluno e reconhecimento das habilidades e competências de cada indivíduo. Ser docente não é uma tarefa fácil, construir um ambiente que facilite o processo de ensino-aprendizagem do aluno menos ainda, porém, é por meio de cursos como o programa de mestrado ESA da UEPA e disciplinas como a de Educação em Saúde na Amazônia que é possível adquirir conhecimento, novas estratégias e prática para capacitar o professor e aprimorar o seu desempenho.

Outros relatos de experiência abordando a aplicação de metodologias de ensino para melhorar os conhecimentos e habilidades dos docentes da área da saúde, podem contribuir com a comunidade científica e servir de base para que os docentes percebam a importância de qualificação para formação docente, além de visualizem com mais clareza como a implementação dessas estratégias de ensino podem ocorrer na prática, objetivos esses alcançado durante esta experiência.

\section{Referências}

Al-Azri, H. \& Ratnapalan, S. (2014). Problem-based learning in continuing medical education: review of randomized controlled trials. Can Fam Physician. $60(2), 157-165$.

Alcântara, L. A. G., Quartieri, M. T., Marchi, M. I., \& Dullius, M. M. (2015). As estratégias de ensino júri simulado e phillips 66 como facilitadores do ensino e da aprendizagem na disciplina de matemática. Revista Eletrônica Sala de Aula em Foco. 4(1), 17-28.

Bodagh, N., Birch, J., \& Ricketts, W. (2017). Problem-based learning: a review. Br J Hosp Med (Lond). 78(11), 167-170.

Burgess, A., Diggele, C. V., Robert, C., \& Mellis, C. (2020). Team-based learning: design, facilitation and participation. BMC Med Educ. 20 (S2), 461.

Colares, K. T. P., \& Oliveira, W. (2018). Metodologias ativas na formação profissional em saúde: Uma revisão. Revista Sustinere. 6(2), 300-320.

Correia, P. R. M., Aguiar, J. G., Viana, A. D, \& Cabral, G. C. P. (2016). Por que vale a pena usar mapas conceituais no ensino superior? Revista Grad mais. 1(1), 41-52.

Costa, N. M. S. C. (2010). Formação pedagógica de professores de medicina. Revista Latino-americana de Enfermagem. $18(1), 7$.

Freitas, D. A., Santos, E. M. S., Lima, L. V. S., Miranda, L. N., Vasconcelos, E. L., \& Nagliate, P. C. (, 2016). Saberes docentes sobre processo ensinoaprendizagem e sua importância para a formação professional em saúde. Interface: Comunicação, saúde e educação. 20(57), 437-448. 
Research, Society and Development, v. 10, n. 8, e46410817572, 2021

(CC BY 4.0) | ISSN 2525-3409 | DOI: http://dx.doi.org/10.33448/rsd-v10i8.17572

Gouvêa, E. P., Odagima, A. M., Shitsuka, D. M., \& Shitsuka, R. (2016). Metodologias ativas: Uma experiência com mapas conceituais. Revista Educação, Gestão e Sociedade. 6(21), 1-11.

Jin, J., \& Bridges, S. M. (2014). Educational Technologies in Problem-Based Learning in Health Sciences Education: A Systematic Review. J Med Internet Res. 16(12), e251.

Koh, Y. Y. J., Schmidt, H. G., Low-Beer, N., \& Rotgans, J. I. (2020). Team-Based Learning Analytics: An Empirical Case Study. Acad Med. 95(6), 872-878.

Lima, V. R., Sousa, E. F. P., \& Sitko, C. M. (2021). Active Learning Methodologies: Flipped Classroom, peer instruction and the simulated jury in teaching Mathematics. Research, Society and Development. 10(5), e2810514507.

Mello, C. C. B., Alves, R. O., \& Lemos, S. M. A. (2014). Metodologias de ensino e formação na área da saúde: Revisão de literatura. Revista CEFAC. 16(6), 2015-2028.

Ministério da Educação. (2018). Diretrizes Curriculares - Cursos de Graduação. http://portal.mec.gov.br/component/content/article?id=12991 .

Mukhopadhyay, K., Mukherjee, S., Dhok, A., Chandan, C., \& Ghosh, J. (2019). Use of concept map as a reinforcement tool in undergraduate curriculum: An analytical study. J Adv Med Educ Prof. 7(3), 118-122.

Pinto, J. B. T., \& Pepe, A. M. (2007). A formação do enfermeiro: contradições e desafios à prática pedagógica. Revista Latino-Americana de Enfermagem. $15(1), 120-126$

Universidade do Estado do Pará. (2021). Programa de pós-graduação Ensino em Saúde na Amazônia. https://paginas.uepa.br/mestradoesa/index.php/mestradoesa/.

Soares, S. R., \& Cunha, M. I. (2010). Formação do professor: A docência universitária em busca de legitimidade. EDUFBA.

Srivastava, A., Srivastava, N., \& Chandrasekharan, S. (2021). Quality of concept maps is affected by map building strategies. Biochem Mol Biol Educ. 49(1), 129-139.

Treviso, P., \& Costa, B. E. P. (2017). Percepção de profissionais da área da saúde sobre a formação em sua atividade docente. Texto e Contexto Enfermagem. 26(1), e5020015.

Valente, G. S. C., \& Viana, L. O. (2010). O ensino de nível superior no brasil e as competências docentes: Um olhar reflexivo sobre esta prática. Práxis Educacional. 6(9), 209-226.

Vieira, S., \& Hossne, W. S. (2015). Metodologia Científica para a área da saúde. (2a ed.), Elsevier.

Wosinski, J., Belcher, A. E., Dürrenbergr, Y., Allin, A., Stormacq, C., \& Gerson, L. (2018). Facilitating problem-based learning among undergraduate nursing students: A qualitative systematic review. Nurse Educ Today. 60, 67-74. 